\title{
Determination of minimum inhibitory concentration (MIC) of some 1,2,4-triazole derivatives with potential tuberculostatic and tuberculocidal ability in vitro
}

\author{
V. V. Zazharskyi', P. O. Davydenko', O. A. Bigdan², A. S. Hotsulia², O. M. Kulishenko', \\ B. V. Gutyj ${ }^{*}$, V. Z. Salata ${ }^{3}$, M. S. Khimych ${ }^{4}$, H. A. Skrypka ${ }^{4}$, O. V. Naidich ${ }^{4}$, \\ M. V. Anforova ${ }^{4}$, I. M. Popova ${ }^{4}$, L. O. Franchuk-Kryva ${ }^{4}$ \\ ${ }^{1}$ Dnipro State Agrarian and Economic University, Dnipro, Ukraine \\ ${ }^{2}$ Zaporizhia State Medical University, Zaporizhia, Ukraine \\ ${ }^{3}$ Stepan Gzhytskyi National University of Veterinary Medicine and Biotechnologies Lviv, Ukraine \\ ${ }^{4}$ Odessa State Agrarian University, Odessa, Ukraine \\ *Corresponding authorE-mail:bvh@ukr.net \\ Received: 18.10.2020. Accepted 29.11.2020
}

\begin{abstract}
The problem of tuberculosis infection caused by multidrug-resistant strains is becoming increasingly important in the world. This infectious disease poses a global health risk with an incidence rate of 8.8 million cases and a fatal outcome of 1.4 million. Coinfection with human immunodeficiency virus (HIV) increases the number of cases of tuberculosis and the development of active tuberculosis. Therefore, the search for substances with potential anti-TB activity is a promising way to solve this problem. 1,2,4-triazole derivatives - one of the interesting classes of anti-TB compounds. The study of their tuberculocidal, tuberculostatic properties, as well as MIC (minimum inhibitory concentration) was promising in relation to mycobacteria of different species. The work was conducted in 2019-2020 at Dnipro State Agrarian and Economic University. M. bovis and M. fortuitum mycobacterial species were selected for the study. The investigation of MIC levels for isoniazid, GKP-305, BKP-100 revealed that the growth of $M$. fortuitum had begun at 12th and 14th day on Sauton and Model media modified with $0.125 \%$ hydrogumate solution, respectively, whereas growth on pure Sauton and Model media was observed on the 25th and 28th day, respectively. It indicates that modification of Sauton and Model media with $0.125 \%$ hydrogumate solution doubles growth rate of $M$. fortuitum. As for isoniazid added to Sauton medium, MIC in case of $M$. fortuitum was impossible to determine since the growth was observed even at $50 \mu \mathrm{g} / \mathrm{mL}$. With respect to GKP-305 added to Sauton medium, MIC was $50 \mu \mathrm{g} / \mathrm{mL}$, which was concluded by the absence of growth. However, in the range of 25 to $0.19 \mu \mathrm{g} / \mathrm{mL}$, isolated flakes of the colony with matte finish up to strong, noticeable strokes of the colonies with matte finish, which become well apparent at shaking, were observed. Having conducted studies on MIC determination on M. bovis and M. fortuitum using various growth media, it was established that MIC for isoniazid, GKP-305, BKP-100 applied on M. fortuitum in Sauton medium was $50 \mu \mathrm{g} / \mathrm{mL}$; on Model medium, only MIC for BKP100 on $M$. fortuitum could be determined, which was $50 \mu \mathrm{g} / \mathrm{mL}$; similar results were obtained for $0.125 \%$ hydrogumate-modified Sauton medium and $0.125 \%$ hydrogumate-modified Model medium (MIC for BKP-100 was $50 \mu \mathrm{g} / \mathrm{mL}$ ). The studies revealed the potential teberculocidal and tuberculostatic ability of the studied drugs GKP-305 and BKP-100 in relation to M. fortuitum and M. bovis. Isoniazid was used as a control. High efficacy was found in BKP-100 in relation to mycobacteria (MIC from 12.5 to 50 $\mu \mathrm{g} / \mathrm{mL})$. GKP-305 showed a tuberculostatic effect.
\end{abstract}

Keywords: Mycobacterium tuberculosis; M. bovis, M. fortuitum; GKP-305; BKP-100; isoniazid.

\section{Introduction}

The tuberculosis infection, which is caused by multidrug-resistant strains of bacteria, is a currently a growing global concern. (Zazharskyi et al., 2019; Palchykov et al., 2019). K. A. Abrahams et al. (2012) have reported that Gram-positive rod-shaped representatives of Mycobacterium tuberculosis ( $M$. tuberculosis) is one of the main human pathogens, which causes tuberculosis (TB). This infectious disease poses a global health threat with 8.8 million yearly cases, 1.4 million of which are lethal. Coinfection with human immunodeficiency virus (HIV) increases frequency of TB and facilitates the development of active tuberculosis. Hence, searching for substances with potential anti-TB activity may pave the way for solving this problem. Derivatives of 1,2,4-triazole represent a group of chemicals with interesting properties, including antitubercular activity. Specifically, the promising tuberculocidic and tuberculostatic properties have been demonstrated, including also minimum inhibitory concentration (MIC) against various mycobacterial species (Zazharskyi et al., 2019; Palchykov et al., 2020). 
In their study, N. Rastogi et al. (2000) have compared the activity of rifapentine and its metabolite (25-O-desacetylrifapentine) in vitro and rifampicin and rifabutin against $M$. tuberculosis, $M$. africanum, M. bovis i M. Bovis in BCG. MIC was determined radiometrically using Middlebrook $7 \mathrm{H} 11$ agar. The bacteriocidic activity was evaluated in parallel and at selected concentrations. Bactec MIC values for substance sensitive $M$. tuberculosisisolates using rifapentine and its 25-O-desacetylrifapentine were 0.03$0.06 \mathrm{mg} / \mathrm{L}$ and $0.125-0.25 \mathrm{mg} / \mathrm{L}$, respectively. Similar MICs have been obtained for $M$. africanum $(0.03-0.125$ and $0.125-0.50$ $\mathrm{mg} / \mathrm{L}$, respectively), and M. bovis(0.063-0.25 and 0.125-1.0 mg/L, respectively), although MIC for BC boviswas way lower (0.008$0.063 \mathrm{mg} / \mathrm{L}$ for rifapentine and $0.016-0.125 \mathrm{mg} / \mathrm{L}$ for its metabolite). MIC values were determined using $7 \mathrm{H} 11$ agar medium, and were one or two dilutions higher than those with the use of Bactec broth. As compared to rifampicin and rifabutin, the inhibitory activity of rifapentin against the substance sensitive isolates was close to the activity of rifabutin, while the inhibition caused by 25-O-desacetylrifapentine was similar to rifampicin. However, rifapentin has been shown to have slightly better bactericidic activity than rifabutin at the same concentration level. Clinical isolates of $M$. tuberculosis possessing high rifampicin resistance (MIC $\geq 32 \mathrm{mg} / \mathrm{L}$ ) were also resistant to rifabutin, rifapentine, and 25-O-desacetylrifapentine, although MICs for rifabutin in this case were slightly lower than those for rifapentin (Rastogi, 2000).

Studies by L. J. McGaw et al. (2008), Zazharskyi V. V. et al. (2019) have denoted that naphthoquinones and other substances showing antimycobaterial activity against tuberculosis mycobacteria were previously obtained from Euclea species. In their research, the authors have used several components extracted from Euclea natalensis and E. undulata, including organic leaf extracts, and evaluated the effect against the zoonosis-causing M. bovis. The group of the studied microorganisms contained $M$. bovis BCG and fast-growing species of $M$. smegmatis and $M$. fortuitum. Acetone extract of $E$. natalensis showed potent activity against $M$. bovis (MIC = $26 \mu \mathrm{g} / \mathrm{mL}$ ). 7-Methyluglon derivative of naphtoquinone has been demonstrated to possess the most potent activity, reaching MIC of up to $1.55 \mu \mathrm{g} / \mathrm{mL}$ the pathogenic M. bovis.

$M$. bovis BCG has been found less sensitive to the studied compounds, compared to the pathogenic strain. $M$. smegmatis appeared to be a better predictor for antimycobacterial activity against the pathogenic M. bovis and M. tuberculosis, while MIC values, obtained using M. fortuitum, correlated well with the values for M. bovis BCG. M. Tato et al. (2006) have reported the activity of linezolid studied on 55 tubercular mycobacteria, including one $M$. bovis and two multidrug-resistant isolates of M. bovis using standard 7H10 agar dilution and standard ESP Culture System II method. Both methods have yielded similar $\mathrm{MIC}_{90}$ values (minimum inhibitory concentration for $90 \%$ of species) at $0.5 \mathrm{mg} / \mathrm{L}$. However, the former method afforded slightly lower $\mathrm{MIC}_{50}$ values (minimum inhibitory concentration for $50 \%$ of species), namely $0.25 \mathrm{mg} / \mathrm{L}$, while the latter gave $0.5 \mathrm{mg} / \mathrm{L}$. No difference was noticed between the sensitive and resistant isolates, including multidrug-resistant isolates of $M$. bovis with MIC range of $0.12-0.5 \mathrm{mg} / \mathrm{L}$. The authors think that potential role of linezolide in TB-infected organisms requires additional evaluation in vivo.

Gemechu A. et al. (2013) have denoted that crude $80 \%$ methanol extracts of $C$. aurea roots, $O$. basilicum seeds, and the leaves of $A$. abyssinica, C. macrostachyus, and E. camaldulensis possess antimycobacterial activity with MICs ranging from 6.25 to 100 $\mu \mathrm{g} / \mathrm{mL}$. MIC values for $80 \%$ methanol extracts of the components described in an order above was the following: $25-100 \mu \mathrm{g} / \mathrm{mL}$ and $12.5-75 \mu \mathrm{g} / \mathrm{mL}, 25-100 \mu \mathrm{g} / \mathrm{mL}$ and $25-50 \mu \mathrm{g} / \mathrm{mL}, 6.25-50 \mu \mathrm{g} / \mathrm{mL}$ and $12.5-50 \mu \mathrm{g} / \mathrm{mL}, 12.5-100 \mu \mathrm{g} / \mathrm{mL}$ and $18.25-50 \mu \mathrm{g} / \mathrm{mL}$ and $6.25-50 \mu \mathrm{g} / \mathrm{mL}$ and $12.5-50 \mu \mathrm{g} / \mathrm{mL}$ for M. tuberculosis and M. bovis, respectively.

In their study, Ahmad Z. et al. (2012) have shown that MIC for 5-chloropyrazinamide against M. tuberculosis was between 12.5 and $25 \mu \mathrm{g} / \mathrm{mL}$, while the serum inhibition titer ratio was $1: 4$. When analyzed under the same conditions, MIC for pyrazinamide exceeded $100 \mu \mathrm{g} / \mathrm{mL}$, whereas mice's serum did not possess any inhibitory activity passing the dose of $300 \mathrm{mg} / \mathrm{kg}$. 5 Chloropyrazinamide was well tolerated by both non-infected and infected mice at doses of up to 300 and $150 \mathrm{mg} / \mathrm{kg}$, respectively. At the same time, both pure pyrazinamide and in combination showed its regular antimicrobial activity in mice infected with $M$. tuberculosis without demonstrating activity against $M$. bovis, whereas 5-chloropyrazinamide did not show any activity against both $M$. tuberculosis and M. bovis. Pyrazinamide, which is an analogue of nicotinamide, is a first-line anti-TB medication with a unique sterilizing effect. The introduction of pyrazinamide into a combined TB treatment, which includes isoniazid, rifampin, and ethambutol, has been demonstrated to shorten treatment duration and, thus, enabled short-term TB treatment. Pyrazinamide is a prodrug, which is hydrolyzed by mycobacterial pyrazinamidase (nicotinamidaze) into pyrazinoic acid. Pyrazinoic acid is effective against $M$. tuberculosis, although its precise bacteriocidic mechanism of action is yet to be determined, It has been proposed that pyrazinoic acid disrupts membrane transport and energy balance in $M$. tuberculosis, or inhibits fatty acid synthetase I (FAS I). Pyrazinamidase is coded by the pncA gene, and mutations in pncA, which leads to the suppression of activity of amidases, enable resistance development to pyrazinamide in $M$. tuberculosis strains. Pyrazinamidesensitive and resistant isolates are usually sensitive to pyrazinoic acid in vitro, although pyrazinoic acid is inactive in vivo. It has been established that pyrazinoic acid esters and 5-substituted pyrazinoic acid derivatives are active against pyrazinamidesensitive and pyrazinamide-resistant $M$. tuberculosis strains, as well as against naturally pyrazinamide-resistant $M$. bovis, $M$. kansasii, and M. avium isolates, in vitro.

5-Chloropyrazinamide is one of such derivatives, which has also been shown to inhibit the growth of $M$. smegmatis at MIC of $25 \mu \mathrm{g} / \mathrm{mL}$, which is way lower than pyrazinamide $(4000 \mu \mathrm{g} / \mathrm{mL})$. Both pyrazinamide and 5-chloropyrazinamide, along with their acidic form 5-chloropyrazinoic acid, have been investigated for in vitro activities against M. tuberculosis, M. bovis (which is initially resistant to pyrazinamide due to nicotinamidase deficiency) and a range of non-tubercular mycobacteria using broth dilution method. 5-Chloropyrazinamide demonstrates higher activity than pyrazinamide against all of the tested microorganisms. At neutral $\mathrm{pH}, \mathrm{MICs}$ for pyrazinamide and 5-chloropyrazinamide against M. tuberculosis range between 32 and $2048 \mu \mathrm{g} / \mathrm{mL}$ and between 8 and $32 \mu \mathrm{g} / \mathrm{mL}$, respectively. MICs for pyrazinoic acid and 5-chloropyrazinoic acid fluctuate between 16 and $64 \mu \mathrm{g} / \mathrm{mL}$ and between 64 and $256 \mu \mathrm{g} / \mathrm{mL}$, respectively.

Therefore, MIC values for 5-chloropyrazinamide and pyrazinoic acid show that M. tuberculosis is more sensitive these substances than to pyrazinamide and 5-chloropyrazinoic acid. Apart from that, pyrazinamide-resistant isolates are still sensitive 
to 5-chloropyrazinamide, pyrazinoic acid, and 5-chloropyrazinoic acid in vitro, which illustrates that 5-chloropyrazinamide does not require the activation of the mycobacterial pyrazinamidaze. It has also been confirmed by the observation that 5chloropyrazinamide, unlike pyrazinamide, is active against $M$. bovis with MIC of $8 \mu \mathrm{g} / \mathrm{mL}$ in vitro and, unlike pyrazinamide, shows activity even at neutral $\mathrm{pH}$.

N. K. Taneja, J. S. Tyagi (2007) have determined MICs for a range of drugs against M. tuberculosis and BCG M. bovis. They used resazurin microtiter assay analysis to test the substances. The obtained results were in good correlation with CFU-based results. Metronidazole and nitrofurans showed mild bactericidal activity using hypoxic resazurin reduction assay. It has been highlighted that hypoxic resazurin reduction assay, unlike conventional CFU count, allows to distinguish between metabolically active and inactive bacteria. Hypoxic resazurin reduction assay assay showed good correctness using both fluorometric and visual approaches to distinguish between bacteriocidic and bacteriostatic effects of a given substance.

The aim of the work is to determination of minimum inhibitory concentration (MIC) of some 1,2,4-triazole derivatives with potential tuberculostatic and tuberculocidal ability in vitro.

\section{Material and methods}

The work was conducted in 2019-2020 at Dnipro State Agrarian and Economic University.

Substances GKP-305 and BKP-100 were synthesized according to the reported procedures at Zaporizhia State Medical University, Zaporizhia, Ukraine (O. A. Bigdan, A. S. Hotsulia). Synthetic studies were performed using reagents from Merck (Darmstadt, Germany) and Sigma-Aldrich (Missouri, USA). The structure and composition of the key synthesized compounds were confirmed by elemental analysis, NMR spectroscopy and chromato-mass spectrometry.

Mycobacterium strain M. bovis 100 passage, which was obtained from biological material of cattle (lymph nodes), isolated and typed by the tuberculosis Department of the regional laboratory of the state food and consumer Service of the Dnipropetrovsk region and M. fortuitum Museum strain ATCC 6841, deposited in the State scientific control Institute of biotechnology and microorganism strains.

M. bovis and $M$. fortuitum mycobacterial species were selected for the study. A broth used as a liquid growth medium for culturing was prepared at a dilution of $1 \mathrm{mg}$ of bacterial culture per $1 \mathrm{~mL}$ of normal saline. The broth was prepared in aseptic conditions of the box using sterile porcelain mortar and pestle with further inoculation into liquid growth media prepared for culturing as specified (Model and Sauton medium) and, respectively, in modifications of these media, namely the combinations with $0.125 \%$ hydrogumate solution and fulvic acids solution. Model medium was prepared as follows: $20 \mathrm{~mL}$ of the medium were weighed into 40 test tubes on analytical balance AXIS AN 200 with the addition of potassium hydrogenphosphate $-1.0 \mathrm{~g}$; ammonium oxalate $-1.0 \mathrm{~g}$; iron (II) sulphate $-0.01 \mathrm{~g}$; magnesium sulfate $-0.1 \mathrm{~g}$; glycerol, pure $-10 \mathrm{~cm}^{3}$; and diluted with Aque purificateae to $200 \mathrm{~cm}^{3}$. Sauton medium was prepared as follows: L-asparagine $-0.8 \mathrm{~g}$; citrate, pure $-0.4 \mathrm{~g}$; potassium hydrogenphosphate - $0.1 \mathrm{~g}$; magnesium sulfate $-0.1 \mathrm{~g}$; iron ammonium citrate - $0.01 \mathrm{~g}$; and diluted with Aque purificateae to $200 \mathrm{~cm}^{3}$. The media were placed into $250 \mathrm{~mL}$ flasks, and then autoclaved during $30 \mathrm{~min}$ at 1,5 atm. Modified Model and Sauton media were prepared by adding $20 \mathrm{~mL}$ of $0.125 \%$ hydrogumate solution and $20 \mathrm{~mL}$ of $0.125 \%$ fulvic acids solution to the corresponding flasks (Zazharskyi et al., 2019; 2019a; 2019b; Palchykov et al., 2019a; Palchykov et al., 2020b).

MICs were afforded by serial dilutions method. MIC values were obtained for isoniazid, $N$-(2-(5-((theophylline-7'-yl)methyl)-4ethyl-1,2,4-triazole-3-ylthio)acetyl)isonicotinohydrazide (GKP-305), 3-(3-fluorophenyl)-6-(4-methoxyphenyl)-7 H-[1,2,4]triazo[3,4$b][1,3,4]$ thiadiazine (BKP-100); media without addition of the studied 1,2,4-triazole derivatives were used for control (Bihdan et al., 2018; Gotsulia et al., 2018).

Solutions of isoniazid, GKP-305, BKP-100 were prepared as follows: $5 \mathrm{~mL}$ of each solution at the concentration of $100 \mu \mathrm{g} / \mathrm{mL}$ were obtained. Then, $2.5 \mathrm{~mL}$ of the corresponding solution were added to $5 \mathrm{~mL}$ of the corresponding growth medium in aseptic conditions of the box and using single-channel automatic pipette (Lenpipet Black, 0.5-5 mL), bubbled few times, drew $2.5 \mathrm{~mL}$ of the solution and added into another test tube, the operation was performed for the 9th test tube in the row of the test tube rack, while the last $2.5 \mathrm{~mL}$ were discarded. The last (10th) test tube was used for control and did not contain tuberculocidal substances. In this way, test tubes containing Model medium, Sauton medium, combination of Model and Sauton media with $0.125 \%$ hydrogumate solution and $0.125 \%$ fulvic acids solution and, respectively, tubes with the additions of isoniazid, GKP305 , BKP-100 in each row at the concentrations of $50 \mu \mathrm{g} / \mathrm{mL} ; 25 \mu \mathrm{g} / \mathrm{mL} ; 12.5 \mu \mathrm{g} / \mathrm{mL} ; 6.25 \mu \mathrm{g} / \mathrm{mL} ; 3.12 \mu \mathrm{g} / \mathrm{mL} ; 1.56 \mu \mathrm{g} / \mathrm{mL} ; 0.78$ $\mu \mathrm{g} / \mathrm{mL} ; 0.39 \mu \mathrm{g} / \mathrm{mL} ; 0.19 \mu \mathrm{g} / \mathrm{mL}$. The last test tube in each row was sued for control, without tuberculostatic agent addition. After culturing, the tubes were placed into TCO-80/1 thermostat and incubated at $37^{\circ} \mathrm{C}$ for 90 days with the monitoring of the initiation of culture growth, its color, and appearance. The cultures were observed for the first 10 days and every 5 days during the remaining of 80 days.

\section{Results}

As a result of MIC studies for isoniazid, GKP-305, BKP-100, it was found that the growth of $M$. fortuitum culture began on days 12 and 14, respectively, on Sauton and Model in combination with $0.125 \%$ solution of humate, and on Sauton and Model respectively on the 25th and 28th day. It can be concluded that the modification of Sauton and Model media with $0.125 \%$ hydrogumate solution allows to 2 times accelerate the growth of colonies of $M$. fortuitum.

The MIC was determined for isoniazid on Sauton medium against $M$. fortuitum as absent because growth was observed even in vitro with a concentration of $50 \mu \mathrm{g} / \mathrm{mL}$.

The MIC was determined for GKP-305 against $M$. fortuitum on Sauton medium as $50 \mu \mathrm{g} / \mathrm{mL}$ in the absence of colony growth. Already in the following tubes from 25 to $0.19 \mu \mathrm{g} / \mathrm{mL}$ was characterized by growth from single flakes of matte color to intensive growth with braids and plaits of matte color, which are clearly visible when shaking (Fig. 1). 


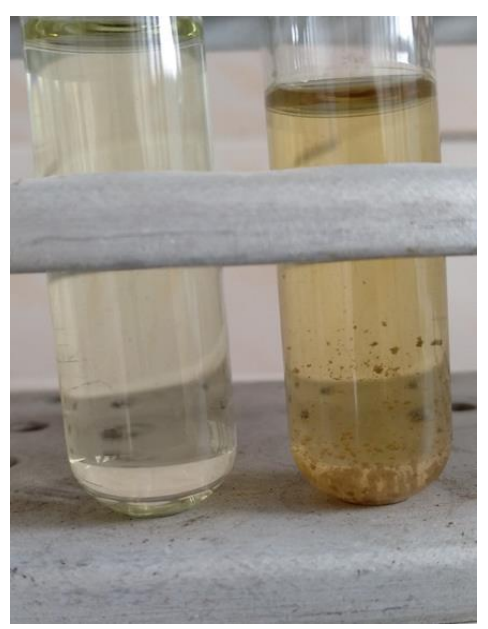

Fig. 1. The growth of M. fortuitum on the medium of Sauton: left test tube - with GKP-305 (MIC 50 mg/kg - no growth); right test tube - without GKP-305 (growth in the form of intense flakes and plaits)

The MIC for the $M$. fortuitum was defined as $25 \mu \mathrm{g} / \mathrm{mL}$ for BKP-100 on Sauton medium.

The growth was characterized from single flakes of matte color to intensive growth with braids and plaits of matte color, which are clearly visible when shaken in the following test tubes (from 12.5 to $0.19 \mu \mathrm{g} / \mathrm{mL}$ ) (Fig. 2).

Accordingly, in the control there was an intensive growth with the formation of braids, plaits and matte flakes (Fig. 2).

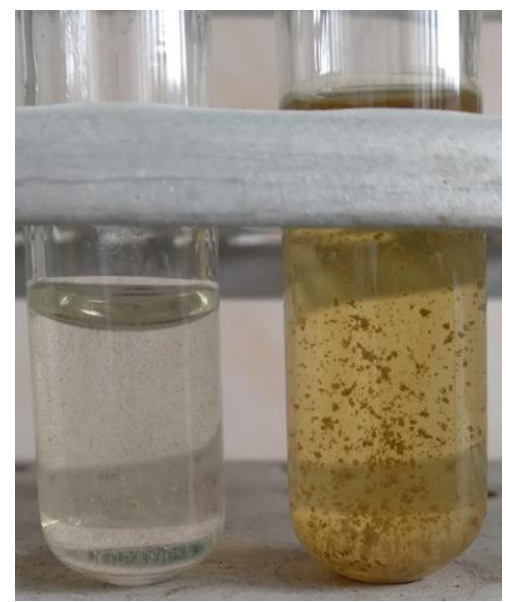

Fig. 2. The growth of $M$. fortuitum on the medium of Sauton: left test tube - with BKP-100 (MIC 50 mg/kg - no growth); right test tube - without BKP-100 (growth in the form of intense flakes and plaits)

The MIC for the $M$. fortuitum was defined for isoniazid on Model medium as absent because in vitro, even at a concentration of $50 \mu \mathrm{g} / \mathrm{mL}$, there was growth in the form of single flakes (Fig. 3).

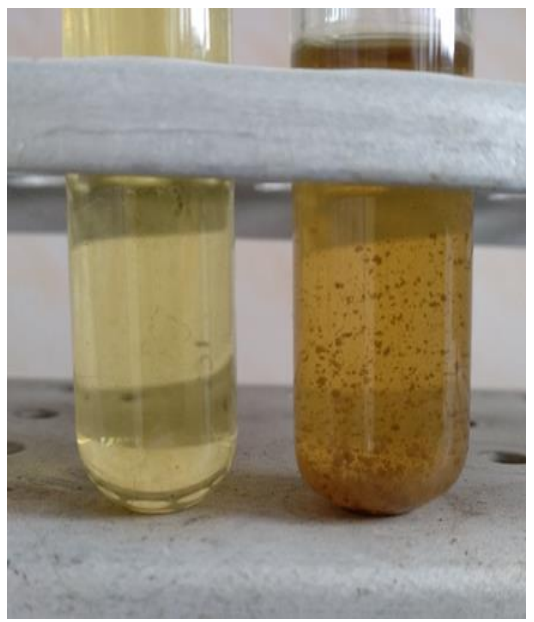

Fig. 3. The growth of $M$. fortuitum on the medium of Sauton: left test tube - isoniasid (the drug isoniazid at a concentration of $50 \mu \mathrm{g} / \mathrm{mL}$, no growth); right test tube - without isoniazid (growth in the form of intense flakes and plaits) 
Tuberculocidal effect of GKP-305 on $M$. fortuitum on Model medium has not been established. The MIC is set as absent or exceeding $50 \mu \mathrm{g} / \mathrm{mL}$ - marked growth of the culture of $M$. fortuitum (Fig. 4). BKP-100 inhibited growth of $M$. fortuitum with an MIC value of $50 \mu \mathrm{g} / \mathrm{mL}$. Subsequent dilutions of BKP-100 showed the appearance of single colonies (MIC $<25 \mu \mathrm{g} / \mathrm{mL})(\mathrm{Fig} .5)$.
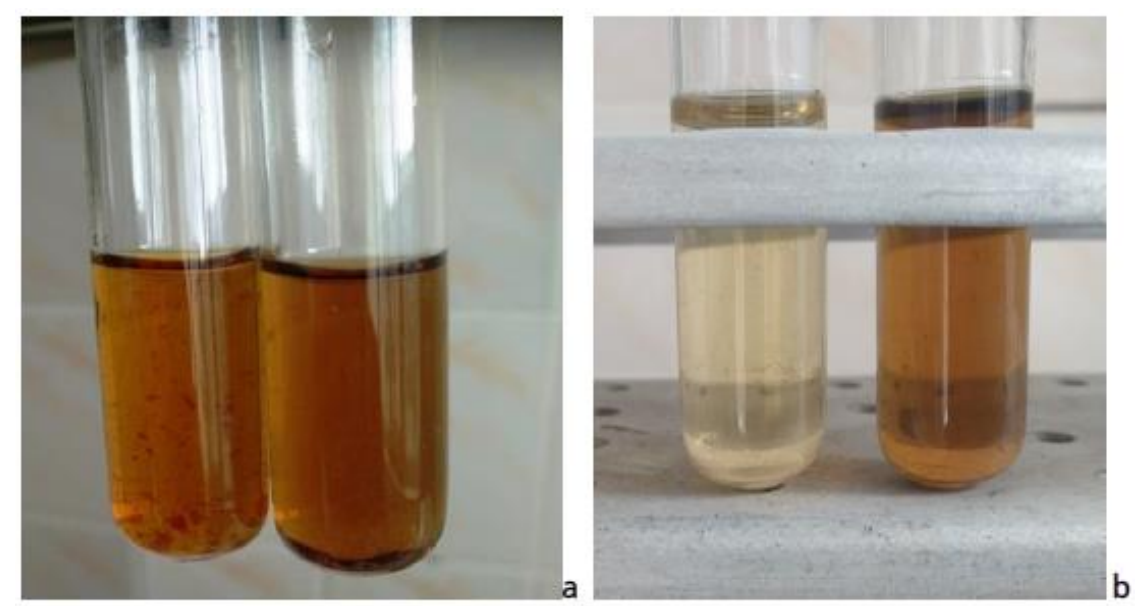

Fig. 4. The growth M. fortuitum on the Model medium: a) left test tube - control without GKP-305 (continuous growth with plaits

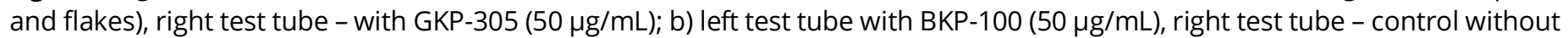
BKP-100

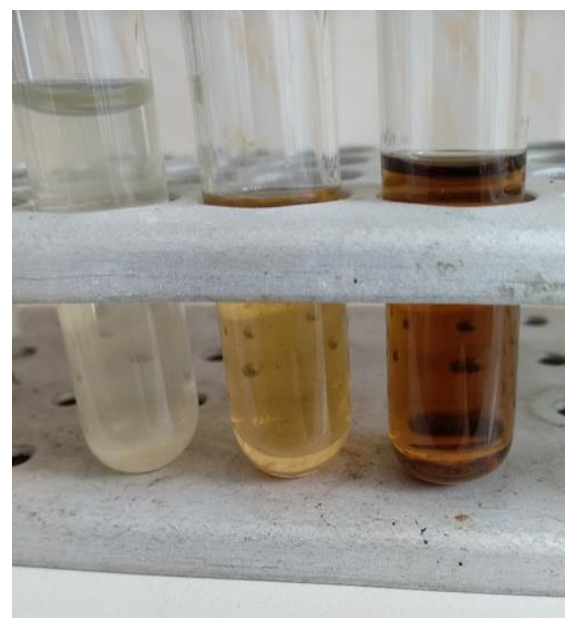

Fig. 5. The growth $M$. fortuitum on the Model medium: left test tube - with BKP-100 (MIC $50 \mu g / m L$, no growth), test tube in the middle - with BKP-100 $(6.25 \mu \mathrm{g} / \mathrm{mL}$, growth in the form of small single flakes), right test tube - without BKP-100 (growth in the form intense flakes)

The MIC was defined for isoniazid in relation to $M$. fortuitum as absent or exceeding $50 \mu g / \mathrm{mL}$ on Sauton medium in combination with $0.125 \%$ hydrogumate solution (Fig. 6).
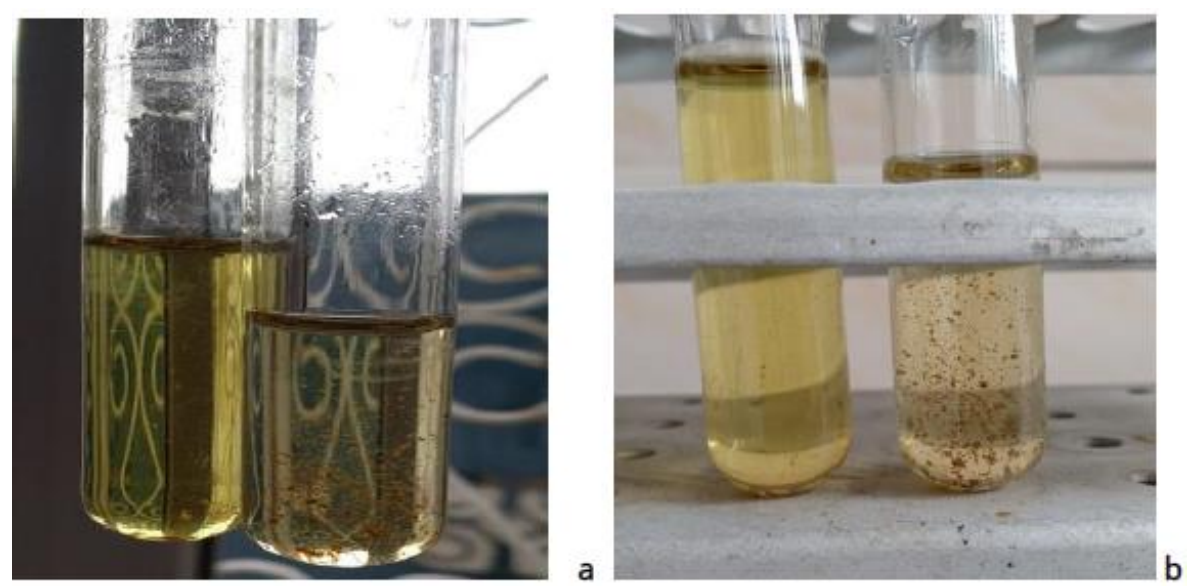

Fig. 6. The growth $M$. fortuitum on the medium of Sauton + hydrogumate: left test tube - isoniazid (50 $\mu \mathrm{g} / \mathrm{mL}$, without growth), right test tube - without isoniazid (growth in the form of intense flakes and plaits) 
MIC for the GKP-305 was established as absent or exceeding $50 \mu \mathrm{g} / \mathrm{mL}$ on the Sauton medium in combination with $0.125 \%$ solution of hydrogumate in relation to M. fortuitum (Fig. 7).
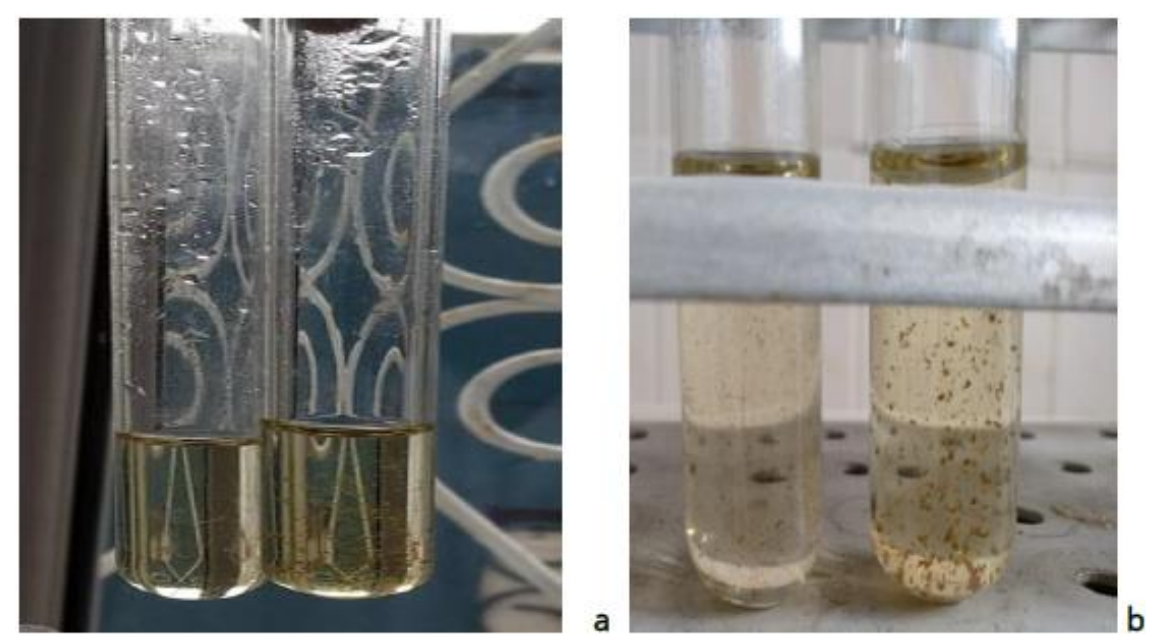

Fig. 7. The growth $M$. fortuitum on the medium of Sauton +hydrogumate: a) left test tube - isoniazid ( $50 \mu g / \mathrm{mL}$, single colonies), right test tube - without isoniazid (growth in the form of intense flakes and plaits); b) left test tube - GKP-305 (50 $\mu$ g/mL, single colonies), right test tube - (growth in the form of intense flakes and plaits)

The MIC for BKP-100 was set as $50 \mu \mathrm{g} / \mathrm{mL}$ on Sauton medium in combination with $0.125 \%$ hydrogumate solution against $M$. fortuitum (Fig. 8).

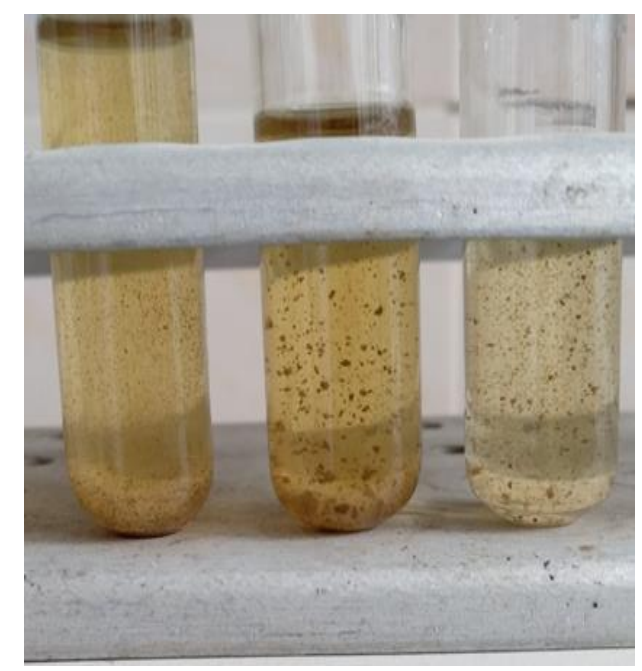

Fig. 8. The growth $M$. fortuitum on the medium of Sauton + Hydrogumate: left test tube - with BKP-100 (MIC $50 \mu \mathrm{Mg} / \mathrm{mL}$, no growth), test tube in the middle - without BKP-100 (growth in the form intense flakes), right test tube - with BKP-100 (6.25 $\mu \mathrm{g} / \mathrm{mL}$, growth in the form of small single flakes)

The MIC for BKP-100 was set as $50 \mu \mathrm{g} / \mathrm{mL}$ on Sauton medium in combination with $0.125 \%$ hydrogumate solution against M. fortuitum (Fig. 9).

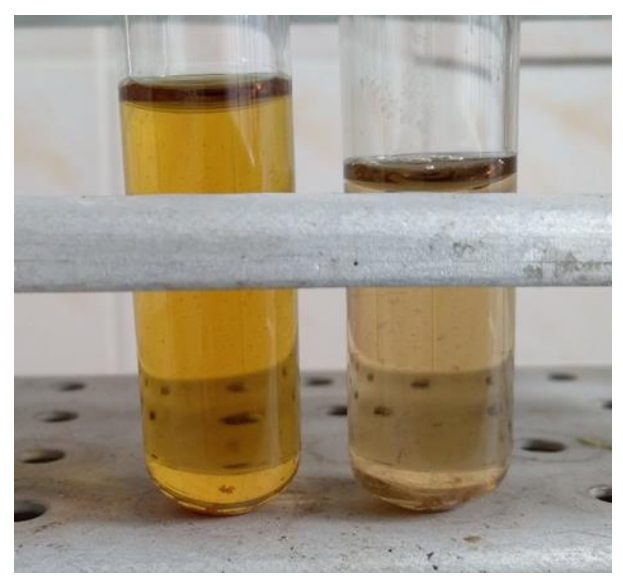

Fig. 9. The growth $M$. fortuitum on the medium of Model + Hydrogumate: left test tube - isoniazid at a concentration $50 \mu g / m L$ (no growth); right test tube - control (growth in the form of intense flakes and plaits) 
The MIC for the drug GKP-305 was established as absent or exceeding $50 \mu \mathrm{g} / \mathrm{mL}$ on Model medium in combination with $0.125 \%$ solution of hydrogumate in relation to M. fortuitum (Fig. 10).

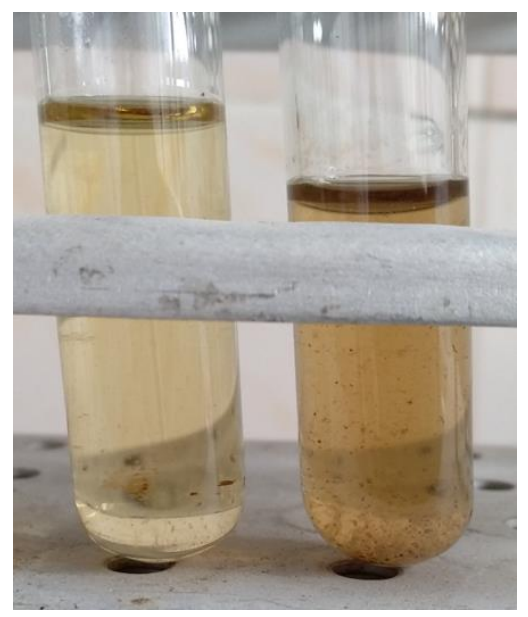

Fig. 10. The growth $M$. fortuitum on the medium of Model + Hydrogumate: left test tube - with GKP-305 (50 $\mu \mathrm{g} / \mathrm{mL}, \mathrm{single}$ colonies), right test tube - control (growth in the form of intense flakes and plaits)

The MIC for BKP-100 was set as $50 \mu \mathrm{g} / \mathrm{mL}$ on Model medium in combination with $0.125 \%$ solution of Hydrogumate against $M$. fortuitum (Fig. 11).

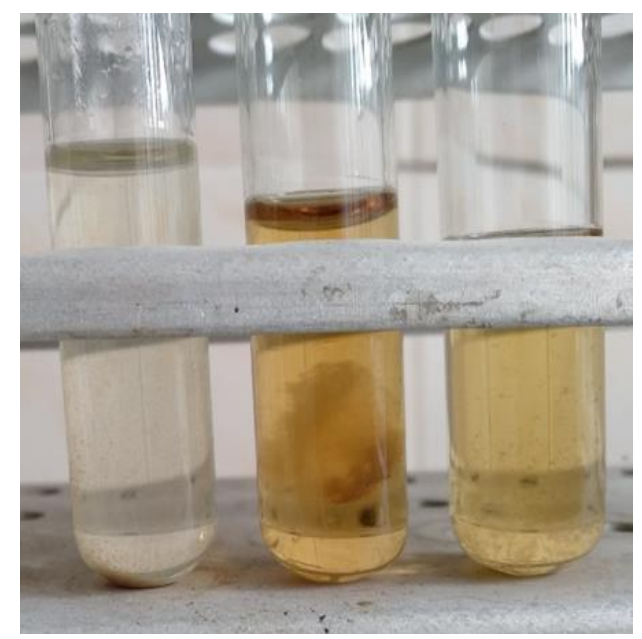

Fig. 11. The growth $M$. fortuitum on the medium of Model + Hydrogumate: left test tube - with BKP-100 (MIC $50 \mu \mathrm{gg} / \mathrm{mL}$, no growth), test tube in the middle - without BKP-100 (growth in the form intense flakes), right test tube - with BKP-100 (6.25 $\mu \mathrm{g} / \mathrm{mL}$, growth in the form of small single flakes)

The MIC was determined for isoniazid $(50 \mu \mathrm{g} / \mathrm{mL})$ on Sauton medium in relation to $M$. bovis. Colony growth was observed at the following concentrations of 25 and $12.5 \mu \mathrm{g} / \mathrm{mL}$ (Fig. 12).

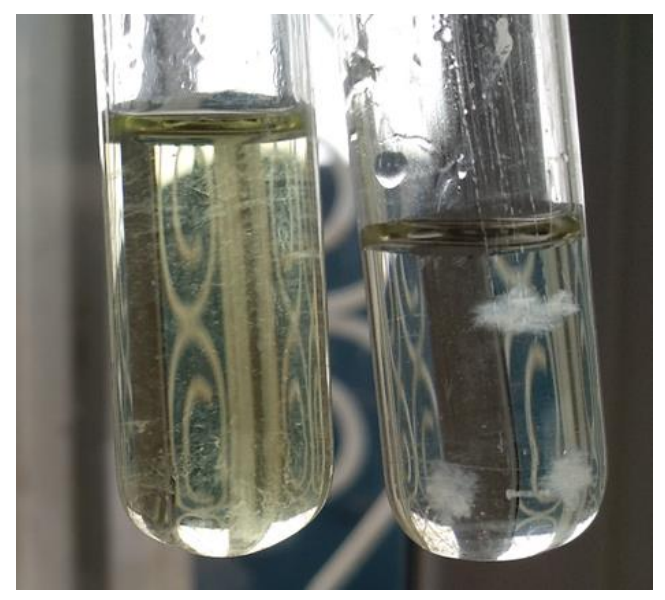

Fig. 12. The growth $M$. bovis on the Sauton medium: left test tube - isoniazid ( $50 \mu \mathrm{g} / \mathrm{mL}$, no growth), right test tube - control (growth in the form of intense flakes and plaits) 
The MIC was determined to be absent for GKP-305 in relation to $M$. bovis because growth was observed even in vitro with a concentration of $50 \mu \mathrm{g} / \mathrm{mL}$. Growth in test tubes was characterized by the formation of single flakes of matte color to intense growth with braids and plaits of matte color, which are clearly visible when shaken (Fig. 13).

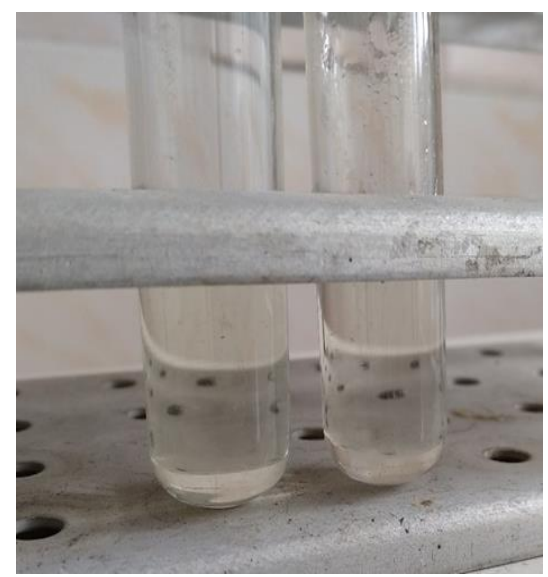

Fig. 13. The growth $M$. bovis on the Sauton medium: left test tube - GKP-305 (50 $\mu \mathrm{g} / \mathrm{mL}$, no growth), right test tube - control (growth in the form of intense flakes and plaits)

The MIC was set as $12.5 \mu \mathrm{g} / \mathrm{mL}$ for BKP-100 on Sauton medium in relation to $M$. bovis. The growth was present in subsequent concentrations (Fig. 14).

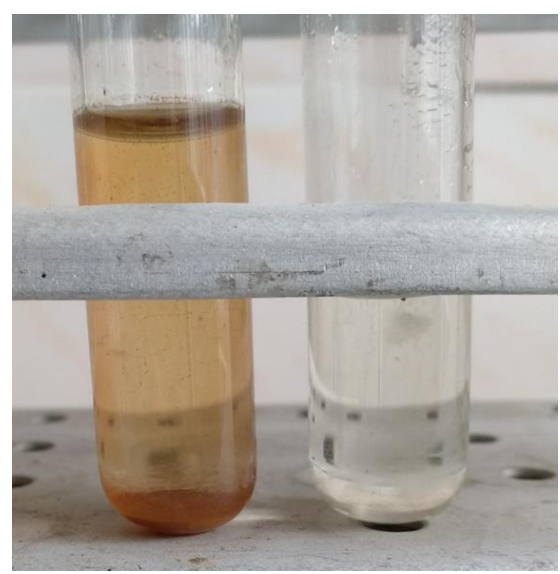

Fig. 14. The growth $M$. bovis on the Sauton medium: left test tube - BKP-100 (50 $\mu \mathrm{g} / \mathrm{mL}$, no growth), right test tube - control (growth in the form of intense flakes and plaits)

The MIC was determined for isoniazid against $M$. bovis on Model medium as absent because in vitro, even at a concentration of $50 \mu \mathrm{g} / \mathrm{mL}$, there was growth in the form of single flakes (Fig. 15).

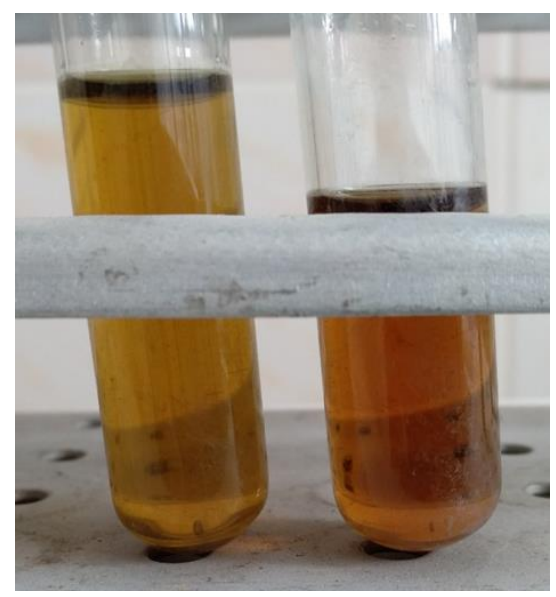

Fig. 15. The growth $M$. bovis on the Model medium: left test tube - isoniazid ( $50 \mu \mathrm{g} / \mathrm{mL}$, no growth), right test tube - control (growth in the form of intense flakes and plaits) 
The MIC was found for GKP-305 against $M$. bovis on Model medium as absent or greater than $50 \mu \mathrm{g} / \mathrm{mL}$ because even in a test tube with a concentration of $50 \mu \mathrm{g} / \mathrm{mL}$ culture growth was observed (Fig. 16).

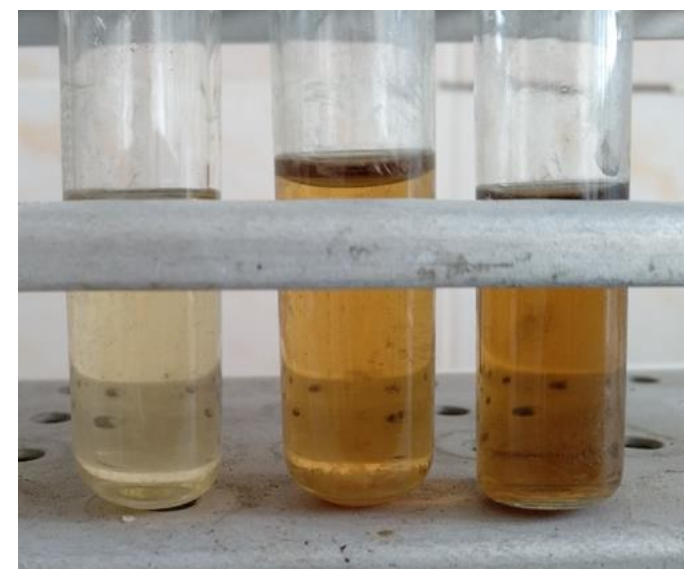

Fig. 16. The growth $M$. bovis on the Model medium: left test tube - GKP-305 (MIC $50 \mu \mathrm{g} / \mathrm{mL}$, no growth), test tube in the middle - control (growth in the form of intense flakes and plaits), right test tube - GKP-305 (6.25 $\mu \mathrm{g} / \mathrm{mL}$, growth in the form of small single flakes)

The MIC was determined for BKP-100 on Model medium for $M$. bovis. single colonies were observed in $50 \mu \mathrm{g} / \mathrm{mL}$ in the next 25 $\mu \mathrm{g} / \mathrm{mL}$ tube, and intensive growth was observed in the control (Fig. 17).

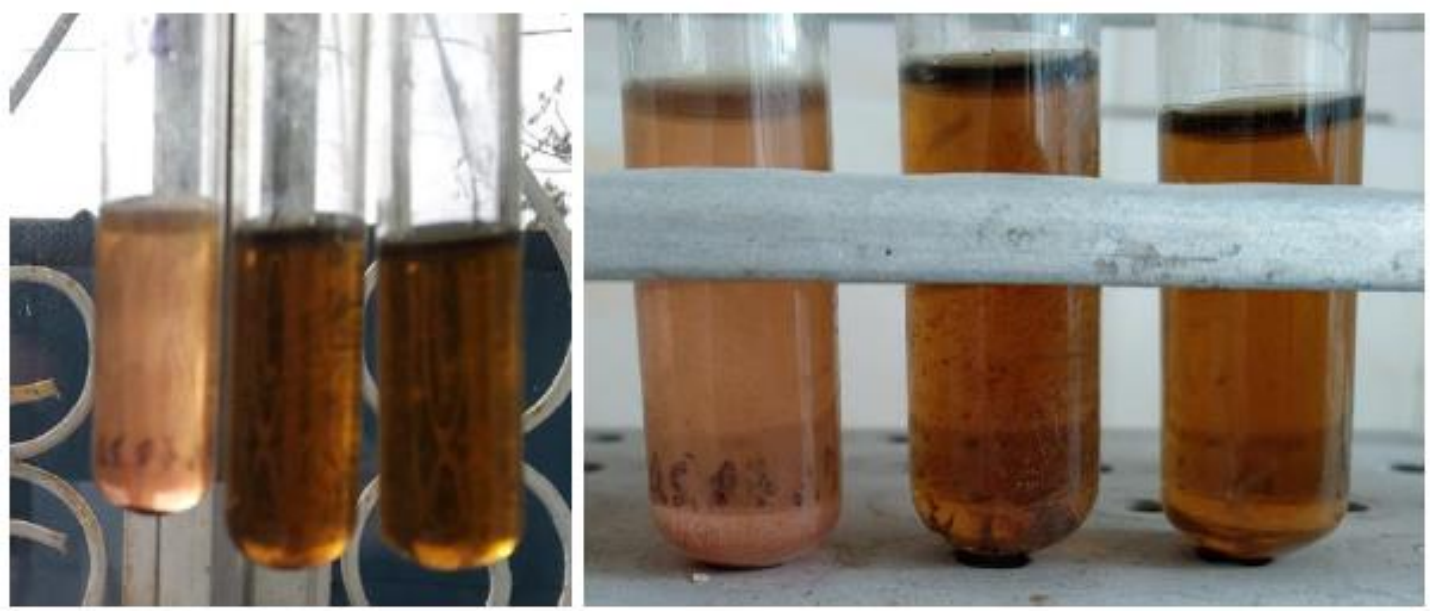

Fig. 17. The growth $M$. bovis on the Model medium: left test tube - BKP-100 (MIC $50 \mu \mathrm{g} / \mathrm{mL}$, no growth), test tube in the middle - control (growth in the form of intense flakes and plaits), right test tube - BKP-100 $(3.1 \mu \mathrm{g} / \mathrm{mL}$, growth in the form of small single flakes)

The MIC was found for isoniazid on Sauton medium in combination with $0.125 \%$ Hydrogumate solution against $M$. bovis as absent or greater than $50 \mu \mathrm{g} / \mathrm{mL}$ (Fig. 18).

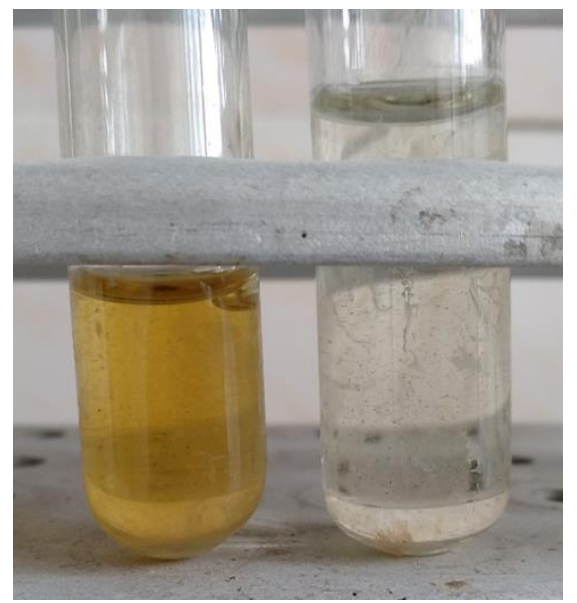

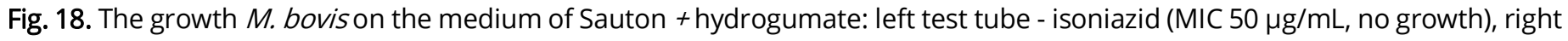
test tube - control (growth in the form of intense flakes and plaits) 
The MIC was found for GKP-305 on Sauton medium in combination with a $0.125 \%$ solution of fulvic acids against $M$. bovis as absent or greater than $50 \mu \mathrm{g} / \mathrm{mL}$ (Fig. 19).

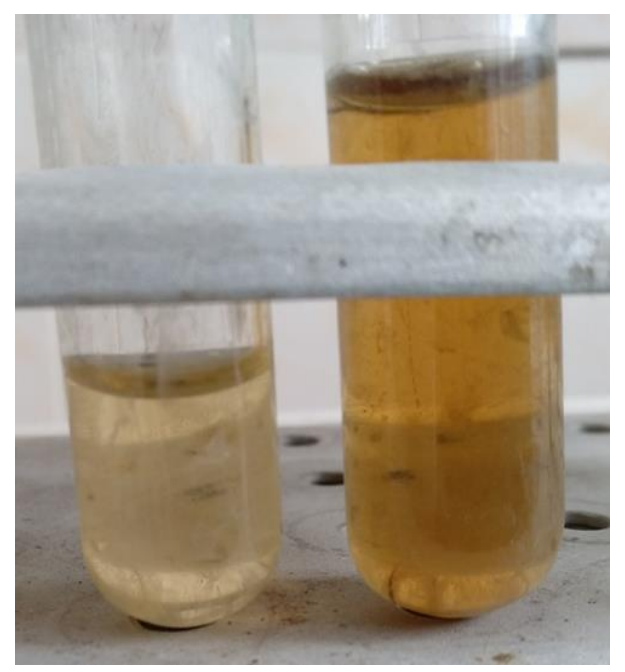

Fig. 19. The growth M. bovis on the medium of Sauton + fulvic acids: left test tube - GKP-305 (MIC $50 \mu \mathrm{g} / \mathrm{mL}$, no growth), right test tube - control (growth in the form of intense flakes and plaits)

The MIC was found for isoniazid against M. bovis on Model medium in combination with $0.125 \%$ Hydrogumate solution as absent or greater than $50 \mu \mathrm{g} / \mathrm{mL}$ (Fig. 20).

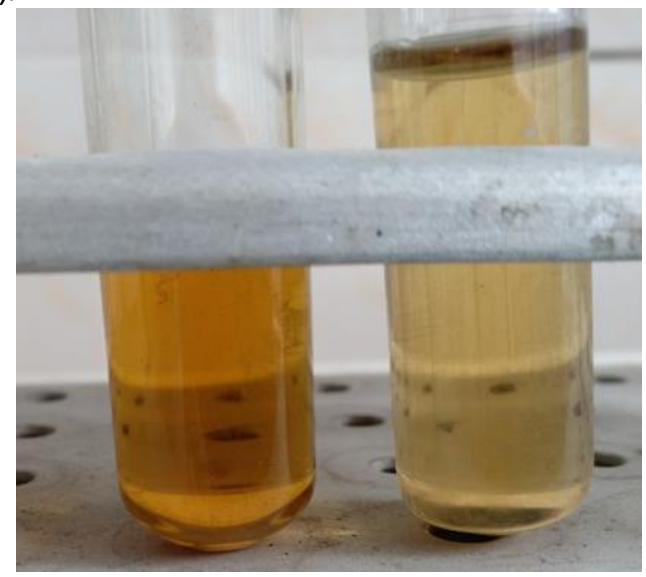

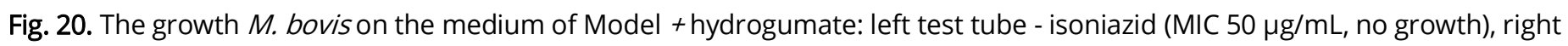
test tube - control (growth in the form of intense flakes and plaits)

The MIC was found for GKP-305 against M. bovis on Model medium in combination with $0.125 \%$ Hydrogumate solution as absent or greater than $50 \mu \mathrm{g} / \mathrm{mL}$ (Fig. 21).

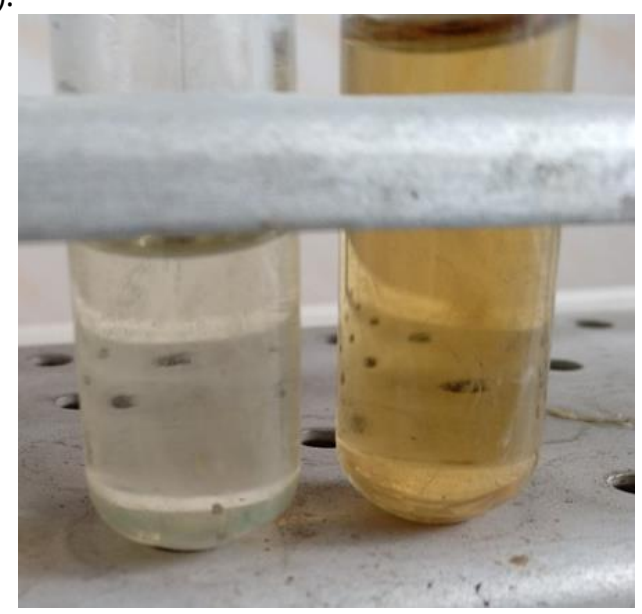

Fig. 21. The growth M. bovis on the medium of Моделя + Hydrogumate: left test tube - GKP-305 (MIC 50 Mg/mL, no growth), right test tube - control (growth in the form of intense flakes and plaits)

The MIC was found for GKP-305 against M. bovis on Sauton medium in combination with $0.125 \%$ Hydrogumate solution as absent or greater than $50 \mu \mathrm{g} / \mathrm{mL}$ (Fig. 22). 


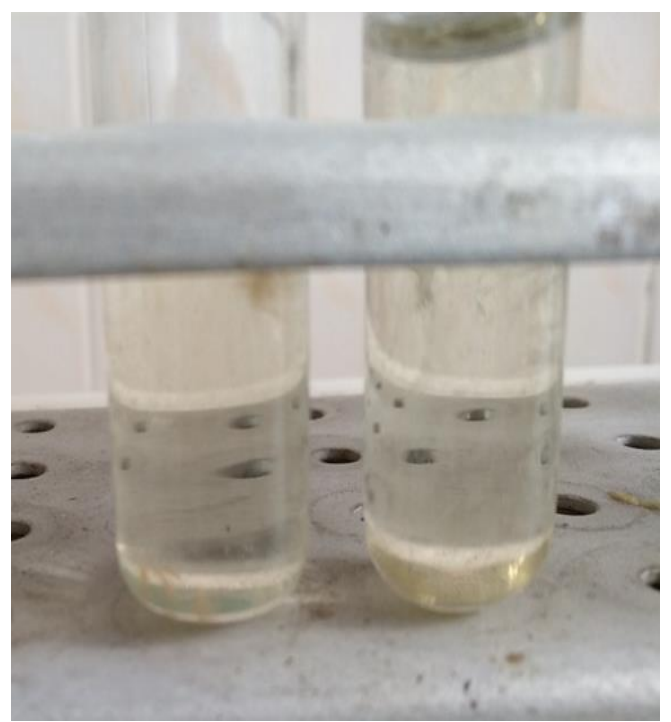

Fig. 22. The growth M. bovis on the medium of Sauton + hydrogumate: left test tube - GKP-305 (MIC $50 \mu \mathrm{g} / \mathrm{mL}$, single colonies), right test tube - control (growth in the form of intense flakes and plaits)

The MIC was found for GKP-305 against M. bovis on Model medium in combination with a $0.125 \%$ solution of fulvic acids as absent or greater than $50 \mu \mathrm{g} / \mathrm{mL}$ (Fig. 23).

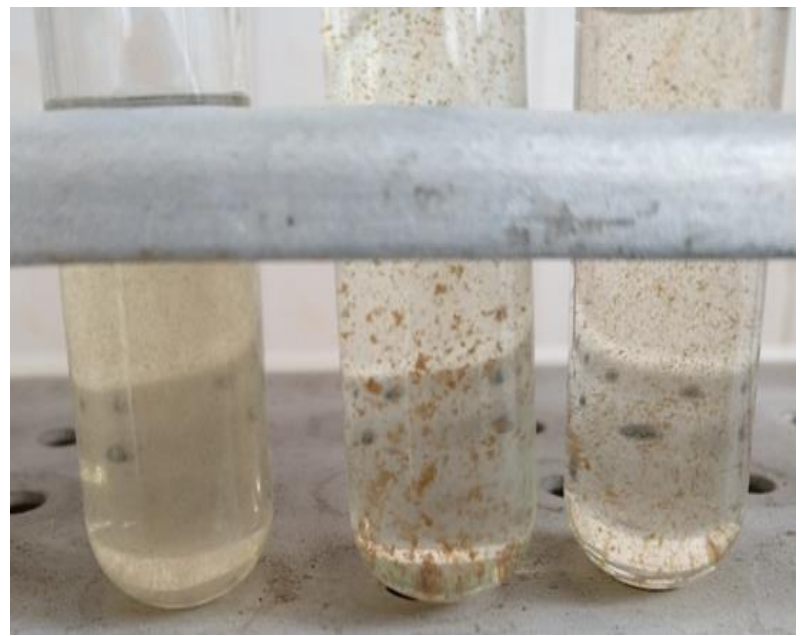

Fig. 23. The growth M. bovis on the medium of Model + fulvic acids: left test tube - GKP-305 (MIC $50 \mu g / m L$, no growth), test tube in the middle - control (growth in the form of intense flakes and plaits), right test tube - GKP-305 (25 $\mu \mathrm{g} / \mathrm{mL}$, growth in the form of small single flakes)

If we compare the growth rate of $M$. bovis colonies on Sauton and Model media in the modification with solutions of hydrogumate and fulvic acids $0.125 \%$, we noted that the growth of mycobacteria with fulvic acids is twice as intense as with hydrogumate (Table 1).

We determined the tuberculocidal ability of BKP-100 for $M$. fortuitum on Sauton medium (MIC $25.0 \mu \mathrm{g} / \mathrm{mL}), \mathrm{Model}(50.0 \mu \mathrm{g} / \mathrm{mL})$, Sauton with hydrogumate $(50.0 \mu \mathrm{g} / \mathrm{mL})$ and Model with the addition of hydrogumate $(50.0 \mu \mathrm{g} / \mathrm{mL})(\mathrm{Table} 2)$.

The GKP-305 exceeds the effectiveness of isoniazid, having bactericidal against $M$. fortuitum on Sauton medium (MIC 50.0 $\mu \mathrm{g} / \mathrm{mL})$ and tuberculostatic on Model medium (12.5-50.0 $\mu \mathrm{g} / \mathrm{mL})$, Sauton with hydrogumate $(25.0-50.0 \mu \mathrm{g} / \mathrm{mL})$ and Model with the addition of hydrogumate $(0.78-50.0 \mu \mathrm{g} / \mathrm{mL}$ ) (Table 2$)$.

The tuberculocidal effect of BKP-100 on M. bovis on Sauton medium was detected (MIK $12.5-50.0 \mu \mathrm{g} / \mathrm{mL}), \mathrm{Model}(25.0-50.0$ $\mu \mathrm{g} / \mathrm{mL}$ ), Sauton + hydrogumate (MIK 12.5 - $50.0 \mu \mathrm{g} / \mathrm{mL}$ ); Sauton + fulvic acids (MIK 12.5 - 50.0 $\mu \mathrm{g} / \mathrm{mL}$ ); Model + hydrogumate (MIK $12.5-50.0 \mu \mathrm{g} / \mathrm{mL})$; Model + fulvic acids $(25-50.0 \mu \mathrm{g} / \mathrm{mL}$ ).

The drug GKP-305 has a tuberculostatic effect against $M$. bovis inhibiting growth on Sauton medium (MIK $1.56-50.0 \mu \mathrm{gg} / \mathrm{mL})$, Model $(1.56-50.0 \mu \mathrm{g} / \mathrm{mL})$, Sauton with hydrogumate $(1.56-50.0 \mu \mathrm{g} / \mathrm{mL})$, Sauton with fulvic acids $(3.12-50.0 \mu \mathrm{g} / \mathrm{mL}), \mathrm{Model}+$ hydrogumate $(0.39-50.0 \mu \mathrm{g} / \mathrm{mL})$ and Model with fulvic acids $(0.78-50.0 \mu \mathrm{g} / \mathrm{mL})$. 


\begin{tabular}{|c|c|c|c|c|c|c|c|c|c|c|c|}
\hline \multirow{2}{*}{$\begin{array}{l}\text { Nutrient } \\
\text { growth } \\
\text { medium }\end{array}$} & \multicolumn{11}{|c|}{ Concentration, $\mu \mathrm{g} / \mathrm{mL}$} \\
\hline & Substance & 50 & 25 & 12.5 & 6.25 & 3.12 & 1.56 & 0.78 & 0.39 & 0.19 & Control \\
\hline \multirow[t]{3}{*}{ Sauton } & Isoniazid & - & + & + & + & + & + & ++ & ++ & ++ & +++ \\
\hline & GKP-305 & + & + & + & + & + & + & ++ & ++ & ++ & +++ \\
\hline & BKP-100 & - & - & - & $+/-$ & + & + & + & + & ++ & +++ \\
\hline \multirow[t]{3}{*}{ Model } & Isoniazid & + & + & + & + & ++ & ++ & ++ & ++ & +++ & +++ \\
\hline & GKP-305 & $+/-$ & + & + & + & + & + & ++ & ++ & ++ & +++ \\
\hline & BKP-100 & - & - & + & + & + & + & + & + & ++ & +++ \\
\hline \multirow{3}{*}{$\begin{array}{c}\text { Sauton + } \\
\text { hydrogumate }\end{array}$} & Isoniazid & $+/-$ & + & + & ++ & ++ & ++ & ++ & +++ & +++ & +++ \\
\hline & GKP-305 & + & + & + & + & + & + & ++ & ++ & ++ & +++ \\
\hline & BKP-100 & - & - & - & + & + & + & + & + & ++ & +++ \\
\hline \multirow{3}{*}{$\begin{array}{c}\text { Sauton + fulvic } \\
\text { acid }\end{array}$} & Isoniazid & $+/-$ & + & + & + & + & ++ & ++ & ++ & +++ & +++ \\
\hline & GKP-305 & + & + & + & + & + & ++ & ++ & ++ & +++ & +++ \\
\hline & BKP-100 & - & - & - & + & + & + & + & + & ++ & +++ \\
\hline \multirow{3}{*}{$\begin{array}{c}\text { Model + } \\
\text { hydrogumate }\end{array}$} & Isoniazid & + & + & + & + & + & ++ & ++ & ++ & ++ & +++ \\
\hline & GKP-305 & + & + & + & + & + & + & + & + & ++ & +++ \\
\hline & BKP-100 & - & - & - & + & + & + & + & + & ++ & +++ \\
\hline \multirow{3}{*}{$\begin{array}{l}\text { Model + fulvic } \\
\text { acid }\end{array}$} & Isoniazid & + & + & + & + & + & ++ & ++ & +++ & +++ & +++ \\
\hline & GKP-305 & + & + & + & + & + & + & + & ++ & ++ & +++ \\
\hline & BKP-100 & - & - & + & + & + & + & + & + & ++ & +++ \\
\hline
\end{tabular}

Note:" "- - no growth; "+" - single colonies; "++" - medium-intensity growth with the formation of braids and plaits; "+++" - high growth intensity with the formation of a large number of flakes and braids

Table 2. MIC of some 1,2,4-triazole derivatives against $M$. fortuitum in vitro

\begin{tabular}{|c|c|c|c|c|c|c|c|c|c|c|c|}
\hline \multirow{2}{*}{$\begin{array}{l}\text { Nutrient } \\
\text { growth } \\
\text { medium }\end{array}$} & \multirow[b]{2}{*}{ Substance } & \multicolumn{9}{|c|}{ Concentration, $\mu \mathrm{g} / \mathrm{mL}$} & \multirow[b]{2}{*}{ Control } \\
\hline & & 50 & 25 & 12.5 & 6.25 & 3.12 & 1.56 & 0.78 & 0.39 & 0.19 & \\
\hline \multirow[t]{3}{*}{ Sauton } & isoniazid & - & + & + & + & ++ & ++ & +++ & +++ & +++ & +++ \\
\hline & GKP-305 & - & + & + & + & + & + & ++ & ++ & ++ & +++ \\
\hline & BKP-100 & - & - & + & + & + & + & + & ++ & ++ & +++ \\
\hline \multirow[t]{3}{*}{ Model } & isoniazid & + & + & ++ & ++ & ++ & ++ & +++ & +++ & +++ & +++ \\
\hline & GKP-305 & + & + & + & ++ & ++ & ++ & +++ & +++ & +++ & +++ \\
\hline & BKP-100 & - & + & + & + & + & + & ++ & ++ & ++ & +++ \\
\hline Sauton + & isoniazid & + & + & + & ++ & ++ & ++ & +++ & +++ & +++ & +++ \\
\hline \multirow[t]{2}{*}{ hydrogumate } & GKP-305 & + & + & ++ & ++ & ++ & ++ & ++ & +++ & +++ & +++ \\
\hline & BKP-100 & - & + & + & + & + & + & ++ & ++ & ++ & +++ \\
\hline Model + & isoniazid & + & + & + & + & + & ++ & ++ & +++ & +++ & +++ \\
\hline \multirow[t]{2}{*}{ hydrogumate } & GKP-305 & + & + & + & + & + & + & + & ++ & ++ & +++ \\
\hline & BKP-100 & - & + & + & + & + & + & + & + & ++ & +++ \\
\hline
\end{tabular}

Note: "-"- no growth; "+"- single colonies; "++"- medium-intensity growth with the formation of braids and plaits; "+++"- high growth intensity with the formation of a large number of flakes and braids

\section{Discussion}

A. Khan et al. (2008) have described in vitro anti-TB potential of 2-nitromidazole. Minimum bactericidal concentrations (MBcCs) for the substance against M. bovis BCG and M. tuberculosis (H37Ra), which replicate actively, were determined to be at 0.226 $\mu \mathrm{g} / \mathrm{mL}$ and $0.556 \mu \mathrm{g} / \mathrm{mL}$, respectively. MICs were 100 times lower than previously reported values for nitroimidazole derivatives, such as nitrofurantoin and furaltadone, which highlights a considerable potential of the heterocycle. 2-Nitroimidazole did not pose any significant effect on saprophytes. It has also been revealed that the substance is active against $M$. tuberculosis, reducing the viability of the bacilli by 2.5 times after 144 hours of incubation at the concentration of $0.113 \mu \mathrm{g} / \mathrm{mL}$. Fivefold concentration $(0.565 \mu \mathrm{g} / \mathrm{mL})$ of 2-nitroimidazole sterilized macrophages of the intercellular pathogens in 192 hours without affecting the host. However, 2-nitroimidazole effectively affect the viability of the dormant non-replicable bacilli of $M$. bovis BCG and $M$. tuberculosis using Wayne model in vitro. Overall, the results demonstrate that 2-nitroimidazole is a potent anti-TB drug with respect to actively replicating bacteria, which also possesses a significant intercellular efficiency.

Zhou et al. (2012) have demonstrated that 18-glycyrrhetinic acid is the main biologically active component of liquorice, possessing various types of activities. The authors have established that both 18 - $\beta$-glycyrrhetinic acid and its derivative with piperazine moiety demonstrate potent antimycobacterial properties, even impacting the drug-resistant $M$. bovis. More importantly, these compounds have been shown to have synergic effect when combined with first-line medications, such as isoniazid, rifampicin, and streptomycin against the clinical $M$. bovis, including drug-resistant strains. In combination with the sub-inhibitory concentration of 18- $\beta$-glycyrrhetinic acid, MICs for the anti-TB drugs was 4 to 16,4 to 8 , and 4 to 8 times lower 
for isoniazid (fractional inhibitory concentration index (FICi) 0.125-0.375), rifampicin (FICi 0.118-0.281), and streptomycin (FICi 0.094-0.275), respectively. MICs for first-line medications in the presence of glycyrrhetinic acid-30-piperazine were 4-16-fold reduced: isoniazid (FICi 0.094-0.266), rifampicin (FICi 0.114-0.313), streptomycin (FICi 0.094-0.281). Moreover, MICs for 18- $\beta$ glycyrrhetinic acid or glycyrrhetinic acid-30-piperazine only were significantly reduced 8 to 16 -fold, 8 to 64 -fold, and 8 to 128 fold in the presence of isoniazid, rifampicin, and streptomycin, respectively. These results indicate that 18-ß-glycyrrhetinic acid and its derivatives are promising antimycobacterial drugs.

Arai et al. (2013) determined that biofilm produced by pathogenic bacteria protects them from antibiotics and immune system of the host. During the search for new inhibitors of biofilm formation in Mycobacterium species, the authors have highlighted terpenoids ophiobolin C, ophiobolin $\mathrm{K}$, and ophiobolin $\mathrm{G}$ recovered from the culture of a sea fungus Emericella variecolor. The mentioned ophiobolins inhibit biofilm formation of M. smegmatis with MIC of 4.1-65 $\mu \mathrm{M}$. The specified compounds did not show antimicrobial activity at concentrations at which anti-biofilm activity was observed. Ophiobolin K was also effective against biofilm formation in $M$. bovis BCG and enabled antimicrobial activity of isoniazid.

In the studies conducted by Srivastav et al. (2012), the authors have demonstrated that alkyl-, halo- and amino-derivatives of pyrimidine-based nucleosides were synthesized, and their activity was investigated using M. bovis, M. tuberculosis, and $M$. avium. Among these compounds, 3'-azido-5-ethyl-2',3'-didesoxyuridine has been shown to possess the most potent antimycobacterial activity against $M$. bovis $\left(\mathrm{MIC}_{50}=1 \mu \mathrm{g} / \mathrm{mL}\right.$ ), M. tuberculosis $\left(\mathrm{MIC}_{50}=10 \mu \mathrm{g} / \mathrm{mL}\right.$ ), and $M$. avium $\left(\mathrm{MIC}_{50}=10\right.$ $\mu \mathrm{g} / \mathrm{mL})$.

Sohaskey (2004) has determined MIC for chloramphenicol and diacetyl chloramphenicol against M. tuberculosis and M. bovis. For both species, MIC for chloramphenicol was $5 \mu \mathrm{g} / \mathrm{mL}$. Both species were inhibited by diacetyl chloramphenicol at the concentration of $50 \mu \mathrm{g} / \mathrm{mL}$. However, it is possible that both cultures were actually sensitive to diacetyl chloramphenicol. Most probably, diacetyl chloramphenicol was converted into chloramphenicol, which inhibited the growth of the specified species.

Shishido et al. (2007) have revealed that $M$. bovis bacille Calmette-Guérin (BCG) vaccine is the only viable vaccine against TB due to its highly valuable protective properties and low virulence. However, there were cases of systematic infection caused by this vaccine in individuals with weakened immunity. It is known that isoniazid, RMP, SM, and EMB are effective as anti-TB treatment, hence being used to treat BCG infections. Unfortunately, however, the evidence on sensitivity of vaccine strains of BCG to the mentioned substances is scarce.

Pan et al. (2011) have denoted that there is a substantial demand for new anti-TB medications possessing new mechanisms of action due to growing concern of global TB spread. Having conducted the search for antimycobacterial metabolites among endophytes extracted from mangrove trees, the researchers have established that the active component of the extract from Fusarium sp. is fusaric acid. Antimycobacterial analyses have shown that its complexes with cadmium (II) and copper (II) possess a strong inhibitory activity against $M$. bovis $B C G(\mathrm{MIC}=4 \mu \mathrm{g} / \mathrm{mL})$ and $\mathrm{H} 37 \mathrm{Rv} M$. tuberculosis $(\mathrm{MIC}=10 \mu \mathrm{g} / \mathrm{mL})$ strains, respectively. It is one of the first reports on antimycobacterial activity of Fusarium metabolite and its metal complexes.

Johar et al. (2005) have studied various 5-substituted 2'-desoxyuridines with respect to their inhibitory activity against M. bovis and M. avium. 5-(C1-substituted)-2'-desoxyuridine derivatives appeared to be potent inhibitors of $M$. avium (MIC $90=1-5 \mu \mathrm{g} / \mathrm{mL}$ ). According to the researchers, the nature of the substituents at C-5 in 2'-desoxyuridine range, is the determinant factor of antimycobacterial activity. This new class of inhibitors is promising for research and development of new anti-TB medications. During the search for antimycobacterial substances, Arai et al. (2015) have highlighted nibomycin, which was identified in cultural broth of sea origin Streptomyces $s p$. The compound showed antimicrobial activity against $M$. smegmatis and M. bovis BCG with a MIC of $1.0 \mu \mathrm{g} / \mathrm{mL}$, both in in active growth in aerobic conditions and in hypoxic conditions. The substance was also effective against $M$. tuberculosis, including clinical strains. The studies have revealed that the mechanism of nibomycin activity is linked with the interaction with enzymes, which unwind DNA helices before cell division. As a result, morphological alteration of mycobacterial cells occurs, leading to bacterial cell death.

Fujiwara et al. (2018) have determined that delamanid, a nitrodihydroimidazooxazole derivative, is effective against $M$. tuberculosis. Its mechanism of action involves the disruption of cellular membrane components of M. tuberculosis (namely, mycolic acids). Delamanid is activated by F420 enzymes of the pathogen using nitroreductase Rv3547 as a prodrug.

Sambhaji T. Dhumal et al. (2016) claim that new 2-pyridinesubstituted thiazolyl-5-aryl-1,3,4-oxadiazoles were synthesized in high yields and tested for anti-tuberculosis activity in vitro against M. tuberculosis H37Ra (MTB) and M. bovis BCG. Among them, a number of compounds showed promising activity against BCG $M$. bovis in concentrations less than $3 \mu \mathrm{g} / \mathrm{mL}$. A molecular docking study was also performed on the enzyme mycobacterial enoyl reductase to understand how these molecules bind. The properties of ADME named products were also analyzed.

Desai et al. (2016) have shown in their research that a series of 1,3,4-oxadiazole derivatives based on indole and pyridine synthesized and evaluated them in vitro antitubercular activity against Mycobacterium tuberculosis H37Ra and Mycobacterium bovis BCG in both active and dormant condition. The leading compound showed very good anti-TB activity.

Zhao et al. (2016) have determined that cyadox, mecindox and quinocetone in combination with rifampicin have an additive effect on M. tuberculosis with a fractional inhibitory concentration (FIC) index of 0.75 .

The problem of tuberculosis infection caused by multidrug-resistant strains is becoming increasingly important in the world. Abrahams et al. (2012) advise that gram-positive bacillus Mycobacterium tuberculosis - is the main human pathogen and the causative agent of tuberculosis (TB). This infectious disease poses a global health risk with an incidence rate of 8.8 million cases and a fatal outcome of 1.4 million. Coinfection with human immunodeficiency virus (HIV) increases the number of cases of tuberculosis and the development of active tuberculosis. Therefore, the search for substances with potential anti-TB activity is a promising way to solve this problem. 1,2,4-triazole derivatives - one of the interesting classes of anti-TB compounds. The study of their tuberculocidal, tuberculostatic properties, as well as MIC (minimum inhibitory concentration) was promising in relation to mycobacteria of different species. 
The studies revealed the potential teberculocidal and tuberculostatic ability of the studied drugs GKP-305 and BKP-100 in relation to $M$. fortuitum and $M$. bovis. Isoniazid was used as a control. High efficacy was found in BKP-100 in relation to mycobacteria (MIC from 12.5 to $50 \mu \mathrm{g} / \mathrm{mL}$ ). GKP-305 showed a tuberculostatic effect.

\section{Conclusion}

The investigation of MIC levels for isoniazid, GKP-305, BKP-100 revealed that the growth of $M$. fortuitum had begun at 12 th and 14 th day on Sauton and Model media modified with $0.125 \%$ hydrogumate solution, respectively, whereas growth on pure Sauton and Model media was observed on the 25th and 28th day, respectively. It indicates that modification of Sauton and Model media with $0.125 \%$ hydrogumate solution doubles growth rate of $M$. fortuitum.

As for isoniazid added to Sauton medium, MIC in case of $M$. fortuitum was impossible to determine since the growth was observed even at $50 \mu \mathrm{g} / \mathrm{mL}$.

With respect to GKP-305 added to Sauton medium, MIC was $50 \mu \mathrm{g} / \mathrm{mL}$, which was concluded by the absence of growth. However, in the range of 25 to $0.19 \mu \mathrm{g} / \mathrm{mL}$, isolated flakes of the colony with matte finish up to strong, noticeable strokes of the colonies with matte finish, which become well apparent at shaking, were observed.

Having conducted studies on MIC determination on M. bovis and M. fortuitum using various growth media, it was established that MIC for isoniazid, GKP-305, BKP-100 applied on M. fortuitum in Sauton medium was $50 \mu \mathrm{g} / \mathrm{mL}$; on Model medium, only MIC for BKP-100 on $M$. fortuitum could be determined, which was $50 \mu \mathrm{g} / \mathrm{mL}$; similar results were obtained for $0.125 \%$ hydrogumate-modified Sauton medium and $0.125 \%$ hydrogumate-modified Model medium (MIC for BKP-100 was $50 \mu \mathrm{Mg} / \mathrm{mL}$ ). In conclusion, the best efficiency in MIC determination with respect to M. fortuitum and M. bovis belongs to BKP-100 with MICs of $50 \mu \mathrm{g} / \mathrm{mL}$ and $12.5 \mu \mathrm{g} / \mathrm{mL}$, respectively.

\section{References}

Abrahams, K. A., Cox, J. A., Spivey, V. L., Loman, N. J., Pallen, M. J., Constantinidou, C., Fernández, R., Alemparte, C., Remuiñán, M. J., Barros, D., Ballell, L., Besra, G. S. (2012). Identification of Novel Imidazo[1,2-a]pyridine Inhibitors Targeting M. tuberculosis QcrB. Plos One, 7(12), e52951. doi: 10.1371/journal.pone.0052951

Ahmad, Z., Tyagi, S., Minkowsk, A., Almeida, D., Nuermberger, E. L., Peck, K. M., Welch, J. T., Baughn, A. S., Jacobs, W. R., Jr, \& Grosset, J. H. (2012). Activity of 5-chloro-pyrazinamide in mice infected with Mycobacterium tuberculosis or Mycobacterium bovis. The Indian journal of medical research, 136(5), 808-814.

Arai, M., Kamiya, K., Pruksakorn, P., Sumii, Y., Kotoku, N., Joubert, J.-P., Moodley, P., Han, C., Shin, D., \& Kobayashi, M. (2015). Anti-dormant mycobacterial activity and target analysis of nybomycin produced by a marine-derived Streptomyces sp. Bioorganic \& Medicinal Chemistry, 23(13), 3534-3541. doi: 10.1016/j.bmc.2015.04.033

Arai, M., Niikawa, H., \& Kobayashi, M. (2013). Marine-derived fungal sesterterpenes, ophiobolins, inhibit biofilm formation of Mycobacterium species. Journal of Natural Medicines, 67, 271-275. doi: 10.1007/s11418-012-0676-5

Bihdan, O. A., Parchenko, V. V., Shcherbyna, R. O., \& Safonov, A. A (2018). 1,2,4-Triazole Derivatives with Halogen Substituted Fragments, Their Synthesis, Modification and Biological Properties. Research journal of pharmaceutical biological and chemical sciences, 1(1), 22-29.

Desai, N. C., Somani, H., Trivedi, A., Bhatt, K., Nawale, L., Khedkar, V. M., Jha, P. C., \& Sarkar, D. (2016). Synthesis, biological evaluation and molecular docking study of some novel indole and pyridine based 1,3,4-oxadiazole derivatives as potential antitubercular agents. Bioorganic \& Medicinal Chemistry Letters, 26(7), 1776-1783. doi: 10.1016/j.bmcl.2016.02.043.

Dhumal, S. T., Deshmukh, A. R., Bhosle, M. R., Khedkar, V. M., Nawale, L. U., Sarkar, D., \& Mane, R. A. (2016). Synthesis and antitubercular activity of new 1,3,4-oxadiazoles bearing pyridyl and thiazolyl scaffolds. Bioorganic \& Medicinal Chemistry Letters, 26(15), 3646-3651. doi: 10.1016/j.bmcl.2016.05.093

Fujiwara, M., Kawasaki, M., Hariguchi, N., Liu, Y., \& Matsumoto, M. (2018). Mechanisms of resistance to delamanid, a drug for Mycobacterium tuberculosis. Tuberculosis, 108, 186-194. doi: 10.1016/j.tube.2017.12.006

Gemechu, A., Giday, M., Worku, A., \& Ameni, G. (2013). In vitro Anti-mycobacterial activity of selected medicinal plants against Mycobacterium tuberculosis and Mycobacterium bovis Strains. BMC Complementary Medicine and Therapies, $13,291$. doi: 10.1186/1472-6882-13-291

Gotsulia, A. S., Zazharskyi, V. V., \& Davydenko, P. O. (2018). Synthesis and antituberculosis activity of N-(2-(5-((theophylline-7'yl)methyl)-4-R-4 H-1,2,4-triazole-3-ylthio)acetyl)-isonicotinohydrazides. Zaporozhye medical journal, 20(4), 578-583. doi: 10.14739/2310-1210.2018.4.135677

Johar, M., Manning, T., Kunimoto, D. Y., \& Kumar, R. (2005). Synthesis and in vitro antimycobacterial activity of 5-substituted pyrimidine nucleosides. Bioorganic \& Medicinal Chemistry, 13(24), 6663-6671, doi: 10.1016/j.bmc.2005.07.046

Khan, A., Sarkar, S., \& Sarkar, D. (2008). Bactericidal activity of 2-nitroimidazole against the active replicating stage of Mycobacterium bovis BCG and Mycobacterium tuberculosis with intracellular efficacy in THP-1 macrophages, International Journal of Antimicrobial Agents, 32(1), 40-45. doi: 10.1016/j.ijantimicag.2008.02.022

McGaw, L. J., Lall, N., Hlokwe, T. M., Michel, A. L., Meyer, J. J., \& Eloff, J. N. (2008). Purified Compounds and Extracts from Euclea Species with Antimycobacterial Activity against Mycobacterium bovis and Fast-Growing Mycobacteria. Biological and Pharmaceutical Bulletin, 31(4), 1429-1433. doi: 10.1248/bpb.31.1429 
Palchykov, V. A., Zazharskyi, V. V., Brygadyrenko, V. V., Davydenko, P. O., Kulishenko, O. M., \& Borovik, I. V. (2020b). Chemical composition and antibacterial effect of ethanolic extract of Buxus sempervirens on cryogenic strains of microorganisms in vitro. Chemical Data Collections, 25, 100323. doi: 10.1016/j.cdc.2019.100323

Palchykov, V. A., Zazharskyi, V. V., Brygadyrenko, V. V., Davydenko, P. O., Kulishenko, O. M., Borovik, I. V., ... Boyko, O. O. (2019a). Bactericidal, protistocidal, nematodicidal properties and chemical composition of ethanol extract of Punica granatum peel. Biosystems Diversity, 27(3), 300-306. doi: 10.15421/011939

Pan, J., Chen, Y., Huang, Y., Tao, Y.-W., Wang, J., Li, Y., Peng, Y., Dong, T., Lai, X.-M., \& Lin, Y.-C. (2011). Antimycobacterial activity of fusaric acid from a mangrove endophyte and its metal complexes. Archives of Pharmacal Research, 34, 1177. doi: 10.1007/s12272-011-0716-9

Rastogi, N., Goh, K. S., Berchel, M., \& Bryskier A. (2000). Activity of rifapentine and its metabolite 25-O-desacetylrifapentine compared with rifampicin and rifabutin against Mycobacterium tuberculosis, Mycobacterium africanum, Mycobacterium bovis and $M$. bovis BCG. Journal of Antimicrobial Chemotherapy, 46(4), 565-570. doi: 10.1093/jac/46.4.565.

Shishido, Y., Mitarai, S., Otomo, K., Seki, M., Sato, A., Yano, I., Koyama, A., \& Hattori, T. (2007). Antituberculosis drug susceptibility testing of Mycobacterium bovis BCG Tokyo strain. The International Journal of Tuberculosis and Lung Disease, 11(12), 1334-1338.

Sohaskey C. D. (2004). Enzymatic inactivation and reactivation of chloramphenicol by Mycobacterium tuberculosis and Mycobacterium bovis. FEMS Microbiology Letters, 240(2), 187-192. doi: 10.1016/j.femsle.2004.09.028

Srivastav, N. C., Shakya, N., Bhavanam, S., Agrawal, A., Tse, C., Desroches, N., Kunimoto, D. Y., \& Kumar, R. (2012). Antimycobacterial activities of 5-alkyl (or halo)-3'-substituted pyrimidine nucleoside analogs. Bioorganic \& Medicinal Chemistry Letters, 22(2), 1091-1094. doi: 10.1016/j.bmcl.2011.11.114

Taneja, N. K., \& Tyagi, J. S. (2007). Resazurin reduction assays for screening of anti-tubercular compounds against dormant and actively growing Mycobacterium tuberculosis, Mycobacterium bovis BCG and Mycobacterium smegmatis. Journal of Antimicrobial Chemotherapy, 60(2), 288-293. doi: 10.1093/jac/dkm207

Tato, M., de la Pedrosa, E. G., Cantón, R., Gómez-García, I., Fortún, J., Martín-Davila, P., Baquero, F., \& Gomez-Mampaso, E. (2006). In vitro activity of linezolid against Mycobacterium tuberculosis complex, including multidrug-resistant Mycobacterium bovis isolates. International Journal of Antimicrobial Agents, 28(1), 75-78. doi: 10.1016/j.ijantimicag.2006.02.011

Zazharskyi, V. V., Davydenko, P. O., Kulishenko, O. M., Borovik, I. V., \& Brygadyrenko, V. V. (2019a). Antimicrobial activity of 50 plant extracts. Biosystems Diversity, 27(2), 163-169. doi: 10.15421/011922

Zazharskyi, V., Parchenko M., Fotina T., Davydenko, P., Kulishenko, Zazharskaya N., \& Borovik I. (2019). Synthesis, structure, physicochemical properties and antibacterial activity of 1,2,4-triazoles-3-thiols and furan derivatives. Voprosy Khimii i Khimicheskoi Tekhnologii, (6), 74-82. doi: 10.32434/0321-4095-2019-127-6-74-82.

Zazharskyi, V., Davydenko, P., Kulishenko, O., Brygadyrenko, V., Zazharska, N. (2019b). Antibacterial activity of herbal infusions against Staphylococcus aureus, Staphylococcus epidermidis and Pseudomonas aeruginosa in vitro. Magyar Allatorvosok Lapja Hungarian Veterinary Journal, 11, 693-704.

Zhao, Y., Cheng, G., Hao, H. Pan, Y., Liu, Z., Dai, M., \& Yuan, Z. (2016). In vitro antimicrobial activities of animal-used quinoxaline 1,4-di-N-oxides against mycobacteria, mycoplasma and fungi. BMC Veterinary Research, 12, 186. doi: 10.1186/s12917016-0812-7

Zhou, X., Zhao, L., Liu, X., Li, X., Jia, F., Zhang, Y., \& Wang, Y. (2012). Antimycobacterial and Synergistic Effects of 18ß-Glycyrrhetinic Acid or Glycyrrhetinic acid-30-piperazine in Combination with Isoniazid, Rifampicin or Streptomycin against Mycobacterium bovis. Phytotherapy Research, 26(2), 253-258. doi: 10.1002/ptr.3536

\section{Citation:}

Zazharskyi, V.V., Davydenko, P.O., Bigdan, O A., Hotsulia, A.S., Kulishenko, O.M., Gutyj, B.V., Salata, V.Z., Khimych, M.S., Skrypka, H.A., Naidich, O.V., Anforova, M.V., Popova, I.M., Franchuk-Kryva, L.O. (2020). Determination of minimum inhibitory concentration (MIC) of some 1,2,4-triazole derivatives with potential tuberculostatic and tuberculocidal ability in vitro. Ukrainian Journal of Ecology, 106), 145-159. 